\title{
Biohydrogenation of 22:6n-3 by Butyrivibrio proteoclasticus P18
}

Jeyamalar Jeyanathan ${ }^{1}$, Marlene Escobar ${ }^{1}$, Robert John Wallace ${ }^{2}$, Veerle Fievez ${ }^{1 *}$ and Bruno Vlaeminck ${ }^{1}$

\begin{abstract}
Background: Rumen microbes metabolize 22:6n-3. However, pathways of 22:6n-3 biohydrogenation and ruminal microbes involved in this process are not known. In this study, we examine the ability of the well-known rumen biohydrogenating bacteria, Butyrivibrio fibrisolvens D1 and Butyrivibrio proteoclasticus P18, to hydrogenate 22:6n-3.

Results: Butyrivibrio fibrisolvens D1 failed to hydrogenate $22: 6 n-3(0.5$ to $32 \mu \mathrm{g} / \mathrm{mL})$ in growth medium containing autoclaved ruminal fluid that either had or had not been centrifuged. Growth of B. fibrisolvens was delayed at the higher 22:6n-3 concentrations; however, total volatile fatty acid production was not affected. Butyrivibrio proteoclasticus P18 hydrogenated 22:6n-3 in growth medium containing autoclaved ruminal fluid that either had or had not been centrifuged. Biohydrogenation only started when volatile fatty acid production or growth of $B$. proteoclasticus P18 had been initiated, which might suggest that growth or metabolic activity is a prerequisite for the metabolism of 22:6n-3. The amount of 22:6n-3 hydrogenated was quantitatively recovered in several intermediate products eluting on the gas chromatogram between 22:6n-3 and 22:0. Formation of neither 22:0 nor 22:6 conjugated fatty acids was observed during 22:6n-3 metabolism. Extensive metabolism was observed at lower initial concentrations of 22:6n-3 $(5,10$ and $20 \mu \mathrm{g} / \mathrm{mL}$ ) whereas increasing concentrations of 22:6n-3 (40 and $80 \mu \mathrm{g} / \mathrm{mL}$ ) inhibited its metabolism. Stearic acid formation (18:0) from 18:2n-6 by B. proteoclasticus P18 was retarded, but not completely inhibited, in the presence of 22:6n-3 and this effect was dependent on 22:6n-3 concentration.

Conclusions: For the first time, our study identified ruminal bacteria with the ability to hydrogenate 22:6n-3. The gradual appearance of intermediates indicates that biohydrogenation of 22:6n-3 by B. proteoclasticus P18 occurs by pathways of isomerization and hydrogenation resulting in a variety of unsaturated 22 carbon fatty acids. During the simultaneous presence of 18:2n-6 and 22:6n-3, B. proteoclasticus P18 initiated 22:6n-3 metabolism before converting 18:1 isomers into 18:0.
\end{abstract}

Keywords: 22:6n-3, Biohydrogenation, Butyrivibrio, Rumen fluid, In vitro, VFA

\section{Background}

Docosahexaenoic acid (22:6n-3) is a poly-unsaturated fatty acid (PUFA) that has been associated with physiological benefits in many species, including human and dairy cows. The amount of 22:6n-3 available for absorption in the small intestine can be increased by intake of marine products (e.g. fish oil, marine algae). However, this is not straightforward in ruminants as extensive biohydrogenation in the rumen leaves little 22:6n-3 for absorption.

\footnotetext{
* Correspondence: veerle.fievez@ugent.be

${ }^{1}$ Laboratory for Animal Nutrition and Animal Product Quality, Ghent

University, Proefhoevestraat 10, 9090 Melle, Belgium

Full list of author information is available at the end of the article
}

Biohydrogenation of PUFA is one of the important microbial processes in the rumen that has a major influence on FA composition of meat and milk. It is well documented that ruminal bacteria are responsible for most of the biohydrogenation process in the rumen [1], and it is thought to be a detoxification mechanism as PUFA are more toxic than saturated FA [2]. Metabolism of linoleic (18:2n-6) and linolenic (18:3n-3) acids is well studied in vivo and in vitro and involves an initial isomerization step to yield a FA with a conjugated double bond (a pair of double bonds separated by one single bond). In vitro studies with mixed and pure rumen bacteria helped to construct the detailed biohydrogenation pathways of $18: 2 n-6$ and $18: 3 n-3$, and the identification 
of bacterial species involved in this process [3-5]. However, information on the biohydrogenation of $22: 6 n-3$ is still lacking. Several reports show extensive metabolism of 22:6n-3 in vivo $[6,7]$ and in vitro with mixed rumen cultures $[8,9]$. However, none of the studies identified bacterial species responsible for its metabolism. Maia et al. [10] investigated PUFA metabolism of 26 predominant rumen bacterial species and found none of them able to metabolize 22:6n-3. Sakurama et al. [11] screened about 100 strains of anaerobic bacteria including some ruminal bacteria and found none of them metabolized 22:6n-3. Pure culture studies focusing on the main rumen hydrogenating bacteria, Butyrivibrio fibrisolvens and Butyrivibrio proteoclasticus also failed to successfully induce 22:6n-3 hydrogenation [10].

The aim of this study was to examine the metabolism of $22: 6 n-3$ by the known biohydrogenating ruminal bacteria, B. fibrisolvens and B. proteoclasticus. To our knowledge, in previous experiments these bacterial species have been exposed to a single concentration of 22:6n-3 $(50 \mu \mathrm{g} / \mathrm{mL})$ which may be toxic for them [10]. We used lower concentrations of 22:6n-3 in our experiments. Additionally, we modified the standard Butyrivibrio growth medium in an attempt to promote biohydrogenation. Experiments 1-5 were conducted using the growth medium containing autoclaved-uncentrifuged rumen fluid and experiments 6-8 were conducted using the growth medium containing autoclaved-centrifuged rumen fluid (Table 1).

\section{Results}

\section{2:6n-3 metabolism by $B$. fibrisolvens $D 1$}

Both autoclaved-centrifuged and -uncentrifuged rumen fluid (Exp. 1 and 6), did not result in 22:6n-3 metabolism at any concentration. The effect of various concentrations of 22:6n-3 on growth, fermentation and biohydrogenation ability of $B$. fibrisolvens D1 (Exp. 6) in media containing $20 \%(\mathrm{v} / \mathrm{v})$ autoclaved-centrifuged rumen fluid are summarized in Table 2. No growth was observed till $48 \mathrm{~h}$ with the highest concentration of 22:6n$3(32 \mu \mathrm{g} / \mathrm{mL})$, whereas a considerably shorter lag phase $(4 \mathrm{~h})$ was observed with the same concentration of $18: 2 n-6$ in the same medium. Optical density $\left(\mathrm{OD}_{600}\right)$ measured at stationary phase was lower $(P<0.05)$ at the concentration of $16 \mu \mathrm{g} / \mathrm{mL}$ compared to the lower concentrations (0 and $8 \mu \mathrm{g} / \mathrm{mL})$. Total volatile fatty acid (VFA) production and VFA profile were not affected $(P>0.05)$ by the $22: 6 n-3$ concentrations. The main fermentation products included butyrate and small amounts of acetate (about $96 \%$ and $4 \%$ of molar concentration of VFA respectively).

\section{2:6n-3 metabolism by B. proteoclasticus P18}

In the growth medium containing $50 \%(\mathrm{v} / \mathrm{v})$ autoclaveduncentrifuged rumen fluid, B. proteoclasticus P18 hydrogenated 22:6n-3 (Exp. 2). At the concentrations of $20 \mu \mathrm{g} /$ $\mathrm{mL}(0.2 \mathrm{mg} /$ tube), most of the 22:6n-3 was metabolized, leaving little residual 22:6n-3 (0.005 $\pm 0.003 \mathrm{mg} /$ tube $)$ after $48 \mathrm{~h}$ of incubation. The type of headspace gas had no influence on the residual amount of 22:6n-3. Total VFA production and VFA profile were not affected $(P>0.05)$ by different gas phases (data not shown). The main fermentation products included butyrate and acetate (about $70 \%$ and $30 \%$ of molar concentration of VFA respectively).

\section{Effect of length of incubation period on 22:6n-3 metabolism by $B$. proteoclasticus $\mathrm{P} 18$}

The extent of 22:6n-3 metabolism in media containing $50 \%(\mathrm{v} / \mathrm{v})$ autoclaved-uncentrifuged rumen fluid at different time points (Exp. 3) is shown in Fig. 1 along with the VFA production at the respective time points. Metabolism of 22:6n-3 $(20 \mu \mathrm{g} / \mathrm{mL})$ initiated after $4 \mathrm{~h}$ and $80 \%$ of 22:6n-3 was hydrogenated between $4 \mathrm{~h}$ and $12 \mathrm{~h}$ of incubation. Accumulation of VFA initiated prior to

Table 1 Overview of the in vitro experiments conducted in this study

\begin{tabular}{|c|c|c|c|c|c|}
\hline Exp. & Autoclaved-rumen fluid/tube (\%) & Bacteria $^{a}$ & $22: 6 n-3(\mu \mathrm{g} / \mathrm{mL})$ & Gas phase $^{\mathrm{b}}$ & Incubation period (h) \\
\hline & Uncentrifuged & & & & \\
\hline 1 & 20 and 50 & B. fibri & 20 & $\mathrm{CO}_{2}$ & 0 and 48 \\
\hline 2 & 50 & B. proteo & 20 & $\mathrm{CO}_{2}, \mathrm{H}_{2}$ and $\mathrm{N}_{2}$ & 0 and 48 \\
\hline 3 & 50 & B. proteo & 20 & $\mathrm{H}_{2}$ & $0,2,4,8,12,24$ and 48 \\
\hline 4 & 50 & B. proteo & $5,10,40$ and 80 & $\mathrm{H}_{2}$ & 0 and 48 \\
\hline \multirow[t]{2}{*}{$5^{c}$} & 50 & B. proteo & 10 and 40 & $\mathrm{H}_{2}$ & $0,2,4,8,12,24$ and 48 \\
\hline & Centrifuged & & & & \\
\hline 6 & 20 and 50 & B. fibri & $0.5,1,2,4,8,16$ and 32 & $\mathrm{CO}_{2}$ & 0 and 48 \\
\hline 7 & 20 & B. proteo & 20 & $\mathrm{H}_{2}$ & 0 and 24 \\
\hline 8 & 20 & B. proteo & 20 & $\mathrm{H}_{2}$ & $0,2,4,8,12$ and 24 \\
\hline
\end{tabular}

${ }^{\mathrm{a}}$ Bacteria used in the experiment -B. fibri: Butyrivibrio fibrisolvens D1; B. proteo: Butyrivibrio proteoclasticus P18

bheadspace gas phase

${ }^{\mathrm{c}}$ The growth medium used in experiment 5 contained $40 \mu \mathrm{g} / \mathrm{mL}$ of $18: 2 n-6$ 
Table 2 Effects of different concentrations of 22:6n-3 on growth, VFA production and biohydrogenation by Butyrivibrio fibrisolvens D1

\begin{tabular}{|c|c|c|c|c|}
\hline & \multicolumn{4}{|c|}{ Concentration of $22: 6 n-3(\mu \mathrm{g} / \mathrm{mL})$} \\
\hline & 0 & 8 & 16 & 32 \\
\hline Lag phase (h) & $<3$ & $<3$ & $4-5$ & $>48$ \\
\hline$O D_{600}^{c}$ & $1.13 \pm 0.07^{\mathrm{a}}$ & $1.22 \pm 0.10^{\mathrm{a}}$ & $1.04 \pm 0.07^{b}$ & $N D^{d}$ \\
\hline Total VFA ( $\mu \mathrm{mol} /$ tube) & $93.0 \pm 3.3$ & $94.0 \pm 6.2$ & $94.2 \pm 4.9$ & ND \\
\hline Biohydrogenation & No & No & No & No \\
\hline
\end{tabular}

Increase in $\mathrm{OD}_{600}$ after $48 \mathrm{~h}$ of incubation compared to initial $\mathrm{OD}_{600}$ at $0 \mathrm{~h}$ ${ }^{\mathrm{d}}$ ND- Not determined as growth was not started till $48 \mathrm{~h}$

Means with different superscripts in $\mathrm{OD}_{600}(\mathrm{a}$ and $\mathrm{b}$ ) are significantly different $(P<0.05)$

the start of 22:6n-3 metabolism and $93 \%$ of VFA were produced within the first $12 \mathrm{~h}$ of the incubation. Both the rate of 22:6n-3 disappearance and VFA production slowed down after $12 \mathrm{~h}$ of incubation. Significant VFA production was not observed after $12 \mathrm{~h}$, whereas hydrogenation of 22:6n-3 slowly continued. As a result, the amount of 22:6n-3 recovered after $48 \mathrm{~h}$ was lower $(P<0.05)$ than the amount recovered after 12 and $24 \mathrm{~h}$ of incubation.

Detailed analysis of chromatograms did not provide evidence of 22:0 formations during metabolism of 22:6n3. Peaks appearance at different time points did not show accumulation of conjugated 22:6 products. The intermediates produced during the $48 \mathrm{~h}$ incubation comprised about 12 different FA (Table 3) and characteristic ion fragments are presented in Table 4. During the early hours of incubation $(<8 \mathrm{~h}), 4$ new peaks (i.e. peaks which were not present in the $0 \mathrm{~h}$ incubation) appeared (Fig. 2a: peaks 1-4). Of these, peak 3 was the most abundant and the molecular ion at $\mathrm{m} / \mathrm{z}=383$ and the loss of the terminal methyl group $(\mathrm{m} / \mathrm{z}=368)$ confirmed the docosapentaenoic acid structure. The odd numbered ion fragment at $\mathrm{m} / \mathrm{z}=153$ is an indication for the location of a $\Delta 5$ double bond [12]. Gaps of $12 \mathrm{amu}$ between $\mathrm{m} / \mathrm{z}=$ 208 and 220; 248 and 260; 288 and 300 and between 328 and 340 confirmed the location of ethylenic double bonds in position $\Delta 10, \Delta 13, \Delta 16$ and $\Delta 19$ (Table 4). Peak 1 showed the same retention time as $22: 5 n-3$ present in the FAME standard and ion fragments at 168 and 180 , 208 and 220, 248 and 260, 288 and 300, and 328 and 340 allowed us to identify this peak as $22: 5 n-3$ [13]. A final docosapentaenoic acid (peak 2) was identified as $\Delta 4, \Delta 10, \Delta 13, \Delta 16, \Delta 19-22: 5$ based on the molecular ion at $\mathrm{m} / \mathrm{z}=383$, gaps of $12 \mathrm{amu}$ between $\mathrm{m} / \mathrm{z}=208$ and 220; 248 and 260; 288 and 300 and between 328 and 340 and the double bond in position 4 is defined by the fingerprint ion at $\mathrm{m} / \mathrm{z}=139$ and 152 [14]. One docosatetraenoic acid was identified as $\Delta 10, \Delta 13, \Delta 16, \Delta 19-22: 4$ (peak 4) based on the molecular ion at $\mathrm{m} / \mathrm{z}=385$ and gaps of $12 \mathrm{amu}$ between $\mathrm{m} / \mathrm{z}=210$ and $222 ; 250$ and 262; 290 and 302 and between 330 and 342. During the further incubation, the abundance of these peaks gradually decreased and were accompanied with the appearance of four 22:3 FA (peaks 5-8: Fig. 2a) and four 22:2 FA (peaks 9-12: Fig. 2a). Peaks 5 and 7 showed a similar mass spectra and were identified as $\Delta 13, \Delta 16, \Delta 20-22: 3$. Ion fragments separated by $12 \mathrm{amu}$ gaps located the double bonds at $\Delta 13, \Delta 16$ and $\Delta 20$ with a prominent ion at $\mathrm{m} / \mathrm{z} 332$ confirming the presence of allylic bonds at $\Delta 16$ and $\Delta 20$. Peak 6 showed the same retention time as $22: 3 n-3$ present in the FAME standard and double

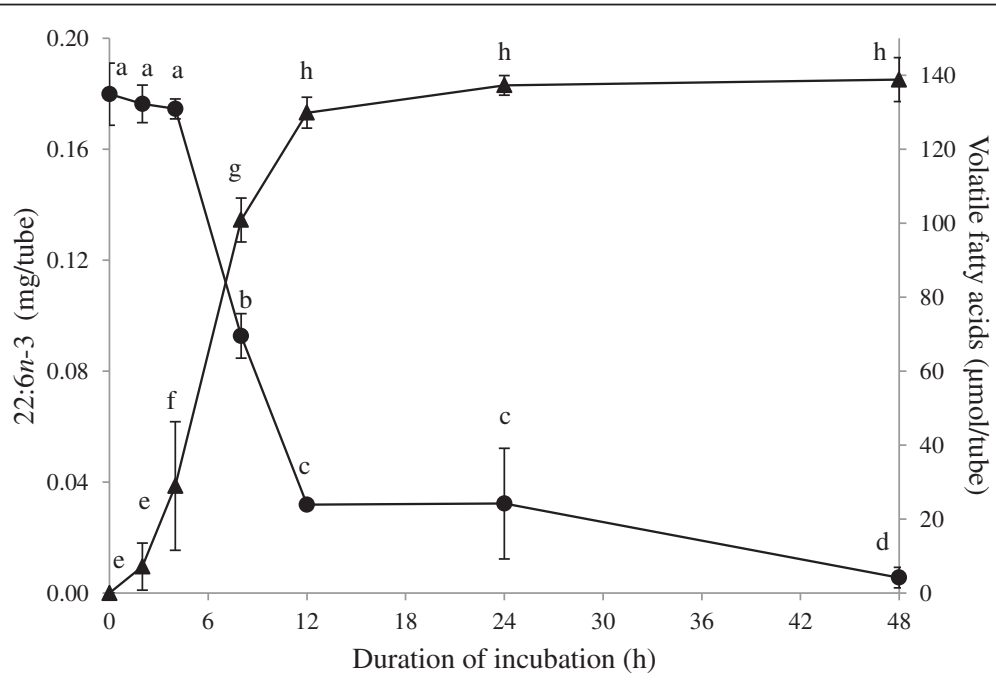

Fig. 1 Metabolism of 22:6n-3 and VFA accumulation at different time points by Butyrivibrio proteoclasticus P18. Growth medium included $50 \%$ $(\mathrm{v} / \mathrm{v})$ of autoclaved-uncentrifuged rumen fluid. Hydrogen was used as the headspace gas. $\bullet$ Residual 22:6n-3 in the tube and $\boldsymbol{\Delta}$ VFA accumulated. Results are means and SD from 2 biological replicates, each of which had 2 analytical replicates. For residual 22:6n-3 and accumulated VFA, data points with different letters are significantly different $(P<0.05)$ 
Table 3 Amount of metabolized 22:6n-3 ( $\mu \mathrm{g} /$ tube) recovered in FAME peaks. Incubation was performed in growth medium containing autoclaved-uncentrifuged rumen fluid (50 \% v/v) in the presence of $22: 6 n-3(20 \mu \mathrm{g} / \mathrm{mL})$ with Butyrivibrio proteoclasticus P18. Tubes were withdrawn at $0,2,4,8,12,24$ and $48 \mathrm{~h}$ incubation to study the extent of 22:6n-3 biohydrogenation. Peak numbers correspond to peaks in Fig. 2

\begin{tabular}{|c|c|c|c|c|c|c|}
\hline \multirow[t]{2}{*}{ Peaks } & & \multicolumn{5}{|c|}{ Incubation duration (h) } \\
\hline & & 4 & 8 & 12 & 24 & 48 \\
\hline 1 & $\Delta 7, \Delta 10, \Delta 13, \Delta 16, \Delta 19-22: 5$ & $2.18 \pm 0.66$ & $16.88 \pm 0.94$ & $16.38 \pm 2.09$ & $3.39 \pm 1.71$ & $2.93 \pm 1.04$ \\
\hline 2 & $\Delta 4, \Delta 10, \Delta 13, \Delta 16, \Delta 19-22: 5$ & - & $3.36 \pm 0.38$ & $4.19 \pm 1.04$ & $1.07 \pm 0.34$ & $0.43 \pm 0.58$ \\
\hline 3 & $\Delta 5, \Delta 10, \Delta 13, \Delta 16, \Delta 19-22: 5$ & $3.92 \pm 1.29$ & $44.38 \pm 1.59$ & $16.60 \pm 5.80$ & $7.40 \pm 3.51$ & $3.68 \pm 2.42$ \\
\hline 4 & $\Delta 10, \Delta 13, \Delta 16, \Delta 19-22: 4$ & & $9.42 \pm 2.55$ & $55.40 \pm 3.00$ & $11.27 \pm 2.34$ & $19.69 \pm 2.41$ \\
\hline 5 & $\Delta 13, \Delta 16, \Delta 20-22: 3$ & & $3.12 \pm 0.70$ & $8.17 \pm 1.99$ & $1.73 \pm 0.11$ & $3.63 \pm 1.62$ \\
\hline 6 & $\Delta 13, \Delta 16, \Delta 19-22: 3$ & & - & $9.91 \pm 1.90$ & $33.05 \pm 4.66$ & $36.02 \pm 5.88$ \\
\hline 7 & $\Delta 13, \Delta 16, \Delta 20-22: 3$ & & - & $0.69 \pm 0.86$ & $4.91 \pm 0.38$ & $7.24 \pm 0.49$ \\
\hline 8 & $\Delta 11, \Delta 16, \Delta 19-22: 3$ & & - & $9.10 \pm 0.99$ & $10.69 \pm 1.66$ & $8.77 \pm 1.22$ \\
\hline 9 & $\Delta 16, \Delta 20-22: 2$ & & - & $0.72 \pm 0.90$ & $7.45 \pm 0.49$ & $10.75 \pm 0.76$ \\
\hline 10 & $\Delta 16, \Delta 19-22: 2$ & & - & $6.31 \pm 1.67$ & $31.24 \pm 2.96$ & $37.31 \pm 4.61$ \\
\hline 11 & $\Delta 16, \Delta 20-22: 2$ & & - & $1.34 \pm 0.93$ & $11.75 \pm 1.25$ & $16.69 \pm 1.46$ \\
\hline 12 & $\Delta 14, \Delta 18-22: 2$ & & - & - & $5.03 \pm 0.48$ & $7.49 \pm 0.56$ \\
\hline
\end{tabular}

bond positions were confirmed by ion fragments separated by 12 amu gaps (Table 4). Peak 8 was identified as $\Delta 11, \Delta 16, \Delta 19-22: 3$ based on ion fragments at 224 and 236, 292 and 304, and 332 and 344. Peaks 9 and 11 showed a similar mass spectra and were identified as $\Delta 16, \Delta 20-22: 2$. Ion fragments separated by 12 amu gaps located the double bonds at $\Delta 16$ and $\Delta 20$ (Table 4) with a prominent ion at $\mathrm{m} / \mathrm{z} 334$ confirming the presence of allylic bonds at $\Delta 16$ and $\Delta 20$. Peak 10 was $\Delta 16, \Delta 19-22: 2$ (ion fragments separated by 12 amu gaps at 294 and 306 , and 334 and 346) and the prominent ion at $\mathrm{m} / \mathrm{z}$ 306 combined ion fragments separated by 12 amu gaps at 266 and 278, and 320 and 332 allowed us to identify peak 12 as $\Delta 14, \Delta 18-22: 2$.

In experiments conducted in media containing autoclaved-centrifuged rumen fluid $(20 \% \mathrm{v} / \mathrm{v})$, B. proteoclasticus hydrogenated 22:6n-3 at the concentration of $20 \mu \mathrm{g} / \mathrm{mL}$ (Exp. 7 and 8). After $24 \mathrm{~h}$ of incubation, little

Table 4 Characteristic ion fragments recorded during gas-chromatography mass-spectrometry analysis of 4,4-dimethyloxazoline derivatives of newly formed fatty acids during biohydrogenation of 22:6n-3 by Butyrivirbio proteoclasticus. Peak numbers correspond to peaks in Fig. 2

\begin{tabular}{|c|c|c|}
\hline Peak & Fatty acid & Characteristic ion fragments ( $\mathrm{m} / \mathrm{z}$, relative intensity) \\
\hline 1 & $\Delta 7, \Delta 10, \Delta 13, \Delta 16, \Delta 19-22: 5$ & $\begin{array}{l}113(64), 126(100), 168(9), 180(24), 194(21), 208(11), 220 \text { (6), } 234 \text { (12), } 248(16), 260 \text { (6), } 274 \text { (12), } 288 \text { (6), } 300 \\
(5), 314(10), 328(3), 340 \text { (2), } 354 \text { (2), } 368 \text { (4), } 383 \text { (9) }\end{array}$ \\
\hline 2 & $\Delta 4, \Delta 10, \Delta 13, \Delta 16, \Delta 19-22: 5$ & $\begin{array}{l}113(100), 126(17), 139(15), 152(49), 166 \text { (52), } 180 \text { (15), } 194(25), 208 \text { (4), } 220(5), 234 \text { (14), } 248 \text { (6), } 260 \text { (7), } 274 \\
(1), 288(8), 300(4), 314(12), 328(3), 340 \text { (2), } 354 \text { (4), } 368 \text { (4), } 383 \text { (11) }\end{array}$ \\
\hline 3 & $\Delta 5, \Delta 10, \Delta 13, \Delta 16, \Delta 19-22: 5$ & $\begin{array}{l}113(100), 126(21), 153(18), 166(4), 180(14), 194(9), 208(1), 220 \text { (3), } 234 \text { (8), } 248(2), 260 \text { (1), } 274(3), 288(2), \\
300(1), 314(4), 328(1), 340(1), 354(1), 368(2), 383 \text { (3) }\end{array}$ \\
\hline 4 & $\Delta 10, \Delta 13, \Delta 16, \Delta 19-22: 4$ & $\begin{array}{l}113(88), 126(100), 168(11), 182(10), 196(13), 210(5), 222(4), 236(6), 250(13), 262(4), 276(12), 290(24), \\
302(8), 316(25), 330(8), 342(5), 356(6), 370(8), 385(28)\end{array}$ \\
\hline $5 / 7$ & $\Delta 13, \Delta 16, \Delta 20-22: 3$ & $\begin{array}{l}113(64), 126(57), 168(9), 182(6), 196(4), 210(4), 224(4), 238 \text { (7), } 252(3), 264 \text { (1), } 278 \text { (8), } 292(7), 304 \text { (3), } \\
318(3), 332(100), 346(2), 358(3), 372(8), 387(17)\end{array}$ \\
\hline 6 & $\Delta 13, \Delta 16, \Delta 19-22: 3$ & $\begin{array}{l}113(100), 126(100), 168(14), 182(11), 196(8), 210(7), 224(7), 238(10), 252(4), 264(2), 278(7), 292(12), \\
304(5), 318(22), 332(16), 344(8), 358 \text { (13), } 372 \text { (15), } 387(42)\end{array}$ \\
\hline 8 & $\Delta 11, \Delta 16, \Delta 19-22: 3$ & $\begin{array}{l}113(80), 126(100), 168(18), 182(11), 196(9), 210(11), 224(7), 236(4), 250(3), 264 \text { (9), } 278 \text { (45), } 292(2), 304 \\
(5), 318(14), 332(6), 344(5), 358(3), 372(15), 387(21)\end{array}$ \\
\hline $9 / 11$ & $\Delta 16, \Delta 20-22: 2$ & $\begin{array}{l}113(100), 126(56), 168(11), 182(7), 196(4), 210(3), 224(3), 238(6), 252(3), 266(4), 280(10), 294(8), 306(1), \\
320(2), 334(75), 348(2), 360(2), 374(6), 389(11)\end{array}$ \\
\hline 10 & $\Delta 16, \Delta 19-22: 2$ & $\begin{array}{l}113(100), 126(69), 168(12), 182(8), 196 \text { (5), } 210 \text { (4), } 224 \text { (6), } 238 \text { (8), } 252 \text { (5), } 266 \text { (6), } 280 \text { (10), } 294 \text { (3), } 306 \text { (2), } \\
320 \text { (13), } 334 \text { (11), } 346 \text { (9), } 360 \text { (10), } 374 \text { (19), } 389 \text { (34) }\end{array}$ \\
\hline 12 & $\Delta 14, \Delta 18-22: 2$ & $\begin{array}{l}113(100), 126(83), 168(14), 182(15), 196(9), 210(6), 224(7), 238 \text { (13), } 252(7), 266(7), 278(3), 292(14), 306 \\
1(80), 320(<1), 332(5), 346(12), 360(25), 374(14), 389(26)\end{array}$ \\
\hline
\end{tabular}




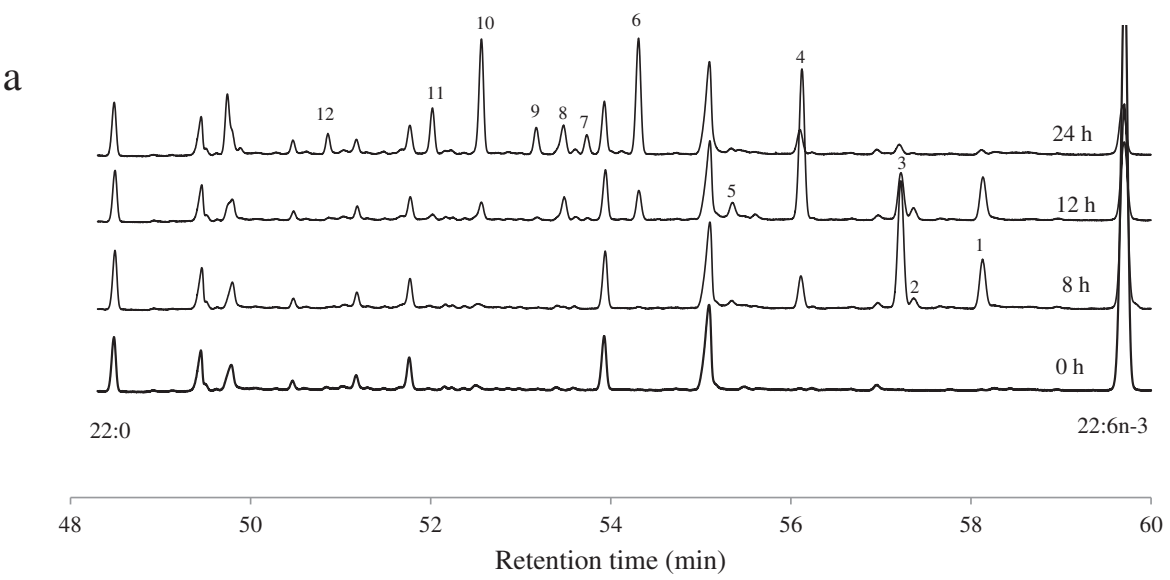

b

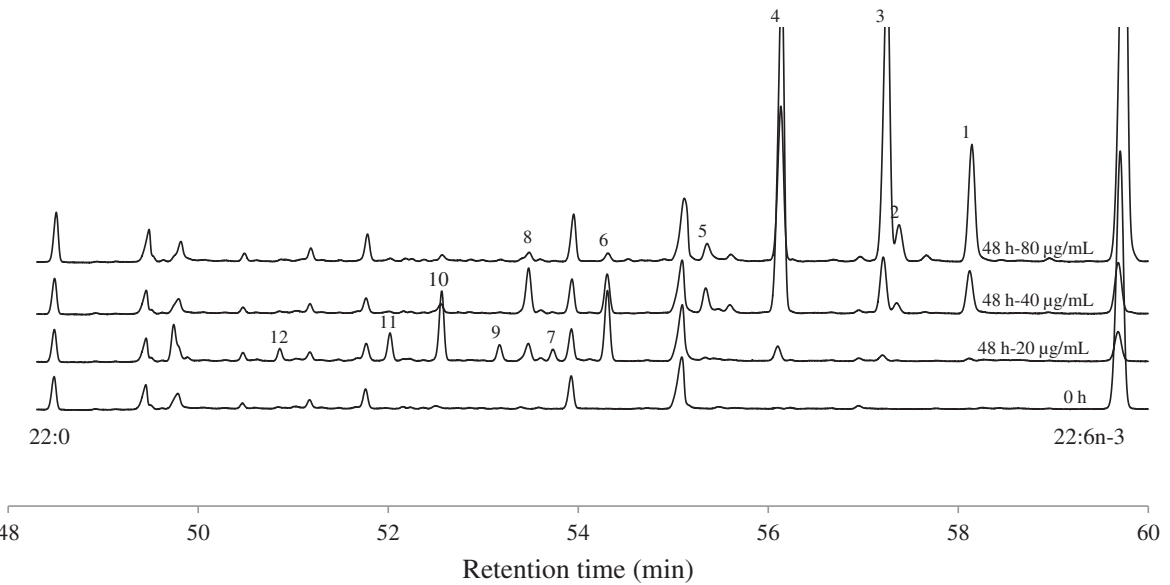

Fig. 2 Partial chromatogram with peaks representing fatty acids from 22:0 to 22:6n-3. These chromatograms obtained from (a) $0,8,12$ and $24 \mathrm{~h}$ incubations with 22:6n-3 (20 $\mu \mathrm{g} / \mathrm{mL})$ and (b) 48 h incubations with 22:6n-3 (20, 40 and $80 \mu \mathrm{g} / \mathrm{mL})$. In both cases Butyrivibrio proteoclasticus P18 had grown in the media containing $50 \%(\mathrm{v} / \mathrm{V})$ autoclaved- uncentrifuged rumen fluid. Peaks visible at $0 \mathrm{~h}$ represent the fatty acids present in the rumen fluid and peaks numbers (1-12) represent new peaks formed during the 22:6n-3 metabolism

residual 22:6n-3 was left in the tube $(0.006 \pm 0.0003 \mathrm{mg} /$ tube). Figure 3 shows the kinetics of 22:6n-3 disappearance along with $\mathrm{OD}_{600}$ measured at the respective time points (Exp. 8). Metabolism of 22:6n-3 initiated after $4 \mathrm{~h}$ and $93 \%$ of 22:6n-3 was hydrogenated between $4 \mathrm{~h}$ and $12 \mathrm{~h}$ of incubation. Growth of B. proteoclasticus (measured as the increase in the $\mathrm{OD}_{600}$ ) initiated prior to the start of 22:6n-3 metabolism and exponentially increased between $4 \mathrm{~h}$ and $12 \mathrm{~h}$. The products formed during the biohydrogenation of 22:6n-3 (Table 5) were identical as those described before (Exp. 3).

\section{Effect of initial concentration of $22: 6 n-3$ on $22: 6 n-3$ metabolism by $B$. proteoclasticus $\mathrm{P} 18$}

The initial concentration of 22:6n-3 influenced the extent of its metabolism. Extensive metabolism of $22: 6 n-3$ was observed at lower concentrations (5, 10 and $20 \mu \mathrm{g} / \mathrm{mL})$.

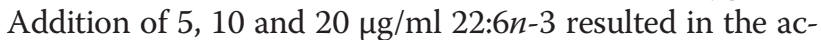
cumulation of 22:2 and 22:3 FA and represented $>80 \%$ of 22:6n-3 that was metabolized during the $48 \mathrm{~h}$ incubation (Table 6). This implies that the initial 22:5 and 22:4 FA were further hydrogenated. An increase in the initial concentration of $22: 6 n-3$ increased the amount of $22: 6 n-3$ metabolized during $48 \mathrm{~h}$ incubation period, but only up to a concentration of about $40 \mu \mathrm{g} / \mathrm{mL}$ (Fig. 4). Although in absolute amounts, more 22:6n-3 disappeared at higher 22:6n-3 concentrations, analysis of the chromatograms showed that extensive biohydrogenation of intermediate products was inhibited (Table 6 and Fig. 2b). At the initial concentration of $40 \mu \mathrm{g} / \mathrm{mL}$, the residual $22: 6 n-3$ retrieved from the tubes after $48 \mathrm{~h}$ incubation was $9 \%$ of the initial amount. Under this condition, $65 \%$ of the metabolized $22: 6 n-3$ accumulated as a single compound identified as $\Delta 10, \Delta 13, \Delta 16, \Delta 19-22: 4$. Further conversion of this product seemed to be inhibited. When the initial 22:6n-3 concentration was increased to $80 \mu \mathrm{g} / \mathrm{mL}$, the residual $22: 6 n-3$ retrieved from the tubes after $48 \mathrm{~h}$ of incubation was $45 \%$ of the initial amount and $>90 \%$ of the 


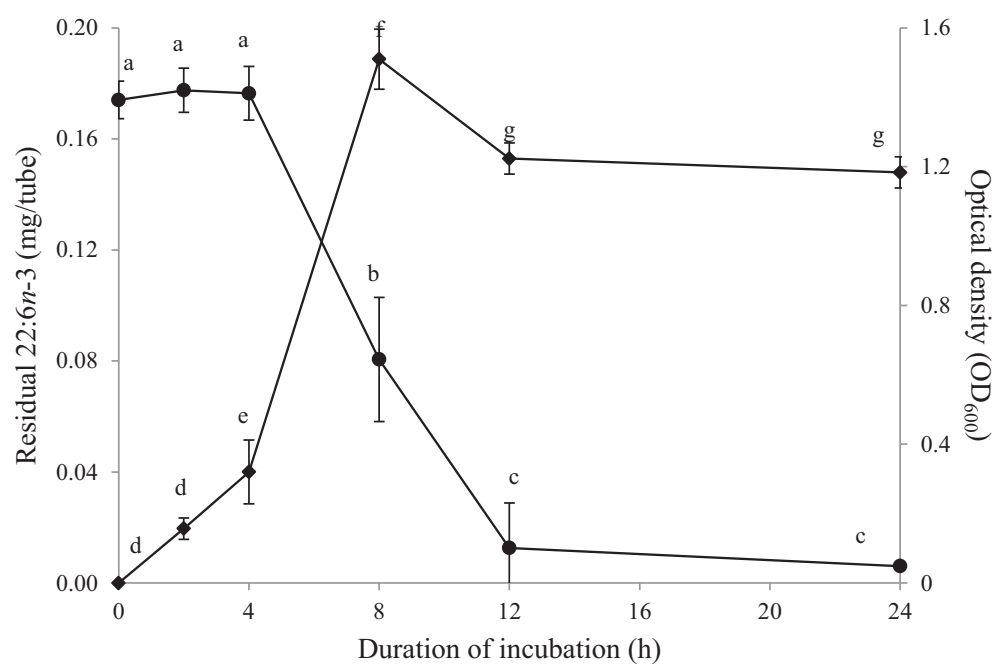

Fig. 3 Metabolism of 22:6n-3 and optical density measurements at different time points by Butyrivibrio proteoclasticus P18. Growth medium included $20 \%(\mathrm{v} / \mathrm{V})$ of autoclaved-centrifuged rumen fluid. Hydrogen was used as the headspace gas. $\bullet$ Residual 22:6n-3 in the tube Optical density $\left(\mathrm{OD}_{600}\right)$ measured at respective time points. Results are means and SD from 3 replicates. For residual 22:6n-3 and $\mathrm{OD}_{600}$ measured, data points with different letters are significantly different $(P<0.05)$

metabolized 22:6n-3 accumulated as 22:4 and 22:5 FA. Subsequent biohydrogenation of these products seemed completely inhibited at this concentration.

Total VFA production was not affected by the initial concentration of 22:6n-3 except for the highest concentration $(80 \mu \mathrm{g} / \mathrm{mL})$. At the highest initial concentration $(80 \mu \mathrm{g} / \mathrm{mL})$ VFA production after $48 \mathrm{~h}$ was higher $(P<0.05)$ compared to the lower concentrations $(16.4 \pm 0.5$ and $15.1 \pm 0.5 \mu \mathrm{mol} / \mathrm{mL}$ respectively), but the VFA profile was not affected $(P>0.05)$.

\section{Effect of presence of $22: 6 n-3$ on $18: 2 n-6$ metabolism by $B$. proteoclasticus $\mathrm{P} 18$}

Table 7 shows the conjugated linoleic acids (CLA), vaccenic acid (VA; trans-11-18:1) and stearic acid (SA;18:0) formation from $40 \mu \mathrm{g} / \mathrm{mL} \mathrm{18:2n-6}$ in presence of 0 (control), low $(10 \mu \mathrm{g} / \mathrm{mL})$ and high $(40 \mu \mathrm{g} / \mathrm{mL}) 22: 6 n-3$, along with VFA formation and residual 22:6n-3. The formation of CLA was observed as soon as inoculation was made. Although formation of CLA and VA were not affected $(P>0.05)$, conversion of VA into SA $(18: 0)$ was

Table 5 Amount of metabolized 22:6n-3 ( $\mu \mathrm{g} /$ tube) recovered in FAME peaks. Incubation was performed in growth medium containing autoclaved-centrifuged rumen fluid $(20 \% \mathrm{v} / \mathrm{v})$ in the presence of $22: 6 n-3(20 \mu \mathrm{g} / \mathrm{mL})$ with Butyrivibrio proteoclasticus P18. Tubes were withdrawn at 0,2,4,8, 12 and $24 \mathrm{~h}$ incubation to study the extent of 22:6n-3 biohydrogenation. Peak numbers correspond to peaks in Fig. 2

\begin{tabular}{|c|c|c|c|c|c|}
\hline \multirow[t]{2}{*}{ Peaks } & & \multicolumn{4}{|c|}{ Incubation duration (h) } \\
\hline & & 4 & 8 & 12 & 24 \\
\hline 1 & $\Delta 7, \Delta 10, \Delta 13, \Delta 16, \Delta 19-22: 5$ & $5.51 \pm 0.59$ & $19.55 \pm 2.82$ & $13.72 \pm 3.93$ & - \\
\hline 2 & $\Delta 4, \Delta 10, \Delta 13, \Delta 16, \Delta 19-22: 5$ & - & $3.68 \pm 1.22$ & $5.21 \pm 3.88$ & - \\
\hline 3 & $\Delta 5, \Delta 10, \Delta 13, \Delta 16, \Delta 19-22: 5$ & $4.41 \pm 1.10$ & $53.32 \pm 8.58$ & $28.37 \pm 39.9$ & - \\
\hline 4 & $\Delta 10, \Delta 13, \Delta 16, \Delta 19-22: 4$ & & $11.34 \pm 3.05$ & $91.90 \pm 40.6$ & $26.41 \pm 36.1$ \\
\hline 5 & $\Delta 13, \Delta 16, \Delta 20-22: 3$ & & $6.89 \pm 1.25$ & $11.86 \pm 3.27$ & $9.34 \pm 5.26$ \\
\hline 6 & $\Delta 13, \Delta 16, \Delta 19-22: 3$ & & - & $10.26 \pm 5.80$ & $38.69 \pm 3.97$ \\
\hline 7 & $\Delta 13, \Delta 16, \Delta 20-22: 3$ & & - & $0.36 \pm 0.32$ & $6.75 \pm 5.59$ \\
\hline 8 & $\Delta 11, \Delta 16, \Delta 19-22: 3$ & & - & $10.10 \pm 6.52$ & $15.73 \pm 16.6$ \\
\hline 9 & $\Delta 16, \Delta 20-22: 2$ & & - & $0.34 \pm 0.30$ & $7.36 \pm 7.36$ \\
\hline 10 & $\Delta 16, \Delta 19-22: 2$ & & - & $1.38 \pm 1.21$ & $26.68 \pm 11.4$ \\
\hline 11 & $\Delta 16, \Delta 20-22: 2$ & & - & - & $10.09 \pm 10.8$ \\
\hline 12 & $\Delta 14, \Delta 18-22: 2$ & & - & - & $6.69 \pm 5.96$ \\
\hline
\end{tabular}


Table 6 Amount of metabolized 22:6n-3 ( $\mu \mathrm{g} /$ tube) recovered in FAME peaks. Incubation was performed in growth medium

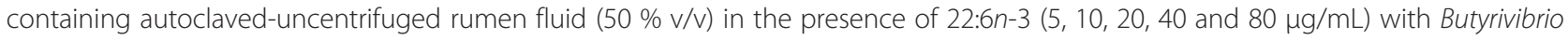
proteoclasticus P18. Tubes were withdrawn at $48 \mathrm{~h}$ of incubation to study the extent of 22:6n-3 biohydrogenation. Peak numbers correspond to peaks in Fig. 2

\begin{tabular}{|c|c|c|c|c|c|c|}
\hline \multirow[b]{2}{*}{ Peaks } & & \multicolumn{5}{|c|}{ Initial concentration of $22: 6 n-3$ ( $\mu \mathrm{g} /$ tube) } \\
\hline & & 50 & 100 & 200 & 400 & 800 \\
\hline 1 & $\Delta 7, \Delta 10, \Delta 13, \Delta 16, \Delta 19-22: 5$ & $0.63 \pm 0.75$ & $1.15 \pm 0.28$ & $2.93 \pm 1.04$ & $25.14 \pm 3.03$ & $77.118 \pm 1.30$ \\
\hline 2 & $\Delta 4, \Delta 10, \Delta 13, \Delta 16, \Delta 19-22: 5$ & - & - & $0.43 \pm 0.58$ & $5.08 \pm 1.05$ & $21.42 \pm 0.69$ \\
\hline 3 & $\Delta 5, \Delta 10, \Delta 13, \Delta 16, \Delta 19-22: 5$ & $0.87 \pm 1.13$ & $1.11 \pm 0.96$ & $3.68 \pm 2.42$ & $29.16 \pm 3.92$ & $177.29 \pm 5.04$ \\
\hline 4 & $\Delta 10, \Delta 13, \Delta 16, \Delta 19-22: 4$ & $5.26 \pm 1.98$ & $8.14 \pm 2.11$ & $19.69 \pm 2.41$ & $208.41 \pm 14.7$ & $78.81 \pm 7.61$ \\
\hline 5 & $\Delta 13, \Delta 16, \Delta 20-22: 3$ & $0.41 \pm 0.82$ & $1.17 \pm 0.82$ & $3.63 \pm 1.62$ & $15.80 \pm 2.34$ & $12.05 \pm 1.17$ \\
\hline 6 & $\Delta 13, \Delta 16, \Delta 19-22: 3$ & $5.82 \pm 0.77$ & $14.26 \pm 0.62$ & $36.02 \pm 5.88$ & $22.22 \pm 3.63$ & $3.48 \pm 1.19$ \\
\hline 7 & $\Delta 13, \Delta 16, \Delta 20-22: 3$ & $2.84 \pm 0.46$ & $5.02 \pm 0.20$ & $7.24 \pm 0.49$ & - & - \\
\hline 8 & $\Delta 11, \Delta 16, \Delta 19-22: 3$ & $2.33 \pm 0.86$ & $4.26 \pm 0.66$ & $8.77 \pm 1.22$ & $26.98 \pm 3.47$ & $5.61 \pm 0.81$ \\
\hline 9 & $\Delta 16, \Delta 20-22: 2$ & $4.14 \pm 0.53$ & $7.14 \pm 0.39$ & $10.75 \pm 0.76$ & - & - \\
\hline 10 & $\Delta 16, \Delta 19-22: 2$ & $7.81 \pm 0.81$ & $15.92 \pm 0.87$ & $37.31 \pm 4.61$ & $5.53 \pm 1.24$ & $3.09 \pm 1.05$ \\
\hline 11 & $\Delta 16, \Delta 20-22: 2$ & $8.83 \pm 0.63$ & $12.94 \pm 0.59$ & $16.69 \pm 1.46$ & - & - \\
\hline 12 & $\Delta 14, \Delta 18-22: 2$ & $3.34 \pm 0.65$ & $5.09 \pm 0.35$ & $7.49 \pm 0.56$ & - & - \\
\hline
\end{tabular}

retarded $(P>0.05)$ in the presence of $22: 6 n-3$ and this effect was dependent on 22:6n-3 concentration. Volatile fatty acids production was not initiated until all the 18:2n-6 had been metabolized and converted into VA regardless of presence of high or low 22:6n-3. Both 18:0 formation and 22:6n-3 metabolism began after the initiation of VFA production. In the control tubes, 18:0 formation started at about $4 \mathrm{~h}$ as soon as VFA production began and this conversion was rapid thereafter (Table 7). In the presence of low 22:6n-3 $(10 \mu \mathrm{g} / \mathrm{mL}), B$. proteoclasticus P18 initiated 22:6n-3 metabolism around $4 \mathrm{~h}$, ahead of 18:0 formation (around $8 \mathrm{~h}$ of incubation). As a result, a small lag phase was observed in 18:0 formation after the initiation of VFA production. In presence of high 22:6n-3 (40 $\mu \mathrm{g} / \mathrm{mL}), 18: 0$ formation was delayed to $12 \mathrm{~h}$ and this conversion was slower thereafter.

\section{Discussion}

Butyrivibrio species are a genetically and functionally diverse group of bacteria present in gastrointestinal systems $[4,15]$. Based on the mechanism of butyrate formation, this group can be classified into two subgroups: vaccenic acid-producing (low butyrate kinase activity) and stearic acid-producing (high butyrate kinase activity). Accordingly, B. fibrisolvens and B. proteoclasticus are belonging to the vaccenic acid-producing and

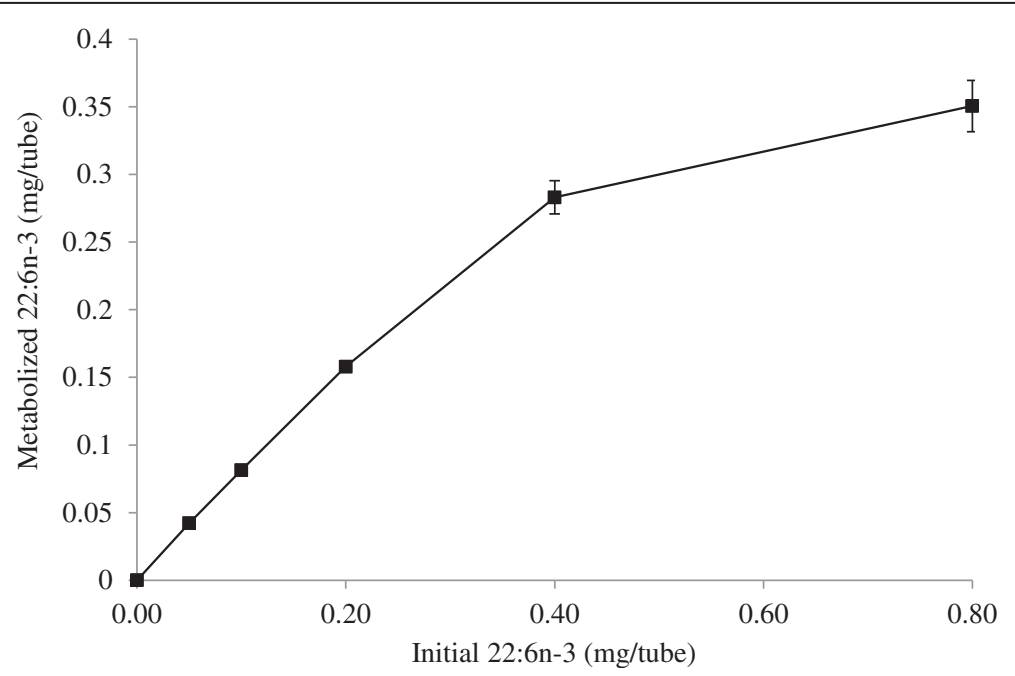

Fig. 4 Effect of initial concentration of 22:6n-3 $(5-80 \mu \mathrm{g} / \mathrm{mL})$ on its metabolism by Butyrivibrio proteoclasticus P18. Incubations were performed in growth medium containing $50 \%(\mathrm{v} / \mathrm{v})$ of autoclaved-uncentrifuged rumen fluid for $48 \mathrm{~h}$ 
Table 7 Linoleic acid metabolism (mg/tube) in presence of 22:6n-3 by B. proteoclasticus P18. Incubation was performed in growth medium containing $40 \mu \mathrm{g} / \mathrm{mL}$ (0.4 mg/tube) of 18:2n-6 in presence of $0,10 \mu \mathrm{g} / \mathrm{mL}$ (Low: $0.1 \mathrm{mg} / \mathrm{tube}$ ) and $40 \mu \mathrm{g} / \mathrm{mL}$ (High: $0.4 \mathrm{mg} /$ tube) 22:6n-3. Growth medium included $50 \%\left(\mathrm{v} / \mathrm{v}\right.$ ) of autoclaved-uncentrifuged rumen fluid and $\mathrm{H}_{2}$ gas was the headspace gas. Value-presented in this table included the fatty acids and VFA of autoclaved-uncentrifuged rumen fluid used to prepare the growth medium

\begin{tabular}{|c|c|c|c|c|c|c|c|c|}
\hline & \multicolumn{8}{|c|}{ Incubation duration (h) } \\
\hline & $22: 6 n-3$ & 0 & 2 & 4 & 8 & 12 & 24 & 48 \\
\hline $18: 2 n-6$ & 0 & $0.27 \pm 0.006^{\mathrm{a}}$ & $0.09 \pm 0.014^{b}$ & $0.08 \pm 0.009^{b c}$ & $0.08 \pm 0.002^{\mathrm{bc}}$ & $0.09 \pm 0.012^{b}$ & $0.06 \pm 0.001^{c}$ & $0.05 \pm 0.002^{c}$ \\
\hline \multirow[t]{2}{*}{ (mg/tube) } & Low & $0.25 \pm 0.007^{\mathrm{a}}$ & $0.09 \pm 0.001^{b c}$ & $0.09 \pm 0.002^{b c}$ & $0.09 \pm 0.001^{b c}$ & $0.10 \pm 0.003^{b}$ & $0.07 \pm 0.006^{c}$ & $0.06 \pm 0.002^{c}$ \\
\hline & High & $0.28 \pm 0.099^{a}$ & $0.11 \pm 0.002^{b}$ & $0.10 \pm 0.011^{b c}$ & $0.10 \pm 0.004^{b}$ & $0.10 \pm 0.006^{b}$ & $0.07 \pm 0.006^{c}$ & $0.06 \pm 0.005^{c}$ \\
\hline CLA & 0 & $0.07 \pm 0.005^{\mathrm{a}}$ & $0.02 \pm 0.007^{b}$ & $0.00^{\mathrm{b}}$ & $0.00^{\mathrm{b}}$ & $0.00^{\mathrm{b}}$ & $0.00^{\mathrm{b}}$ & $0.00^{\mathrm{b}}$ \\
\hline \multirow[t]{2}{*}{ (mg/tube) } & Low & $0.10 \pm 0.007^{a^{*}}$ & $0.02 \pm 0.004^{b}$ & $0.00^{\mathrm{b}}$ & $0.00^{\mathrm{b}}$ & $0.00^{\mathrm{b}}$ & $0.00^{\mathrm{b}}$ & $0.00^{\mathrm{b}}$ \\
\hline & High & $0.11 \pm 0.073^{\mathrm{a}}$ & $0.02 \pm 0.003^{b}$ & $0.00^{\mathrm{b}}$ & $0.00^{\mathrm{b}}$ & $0.00^{\mathrm{b}}$ & $0.00^{\mathrm{b}}$ & $0.00^{\mathrm{b}}$ \\
\hline VA & 0 & $0.05 \pm 0.005^{\mathrm{a}}$ & $0.27 \pm 0.026^{b}$ & $0.21 \pm 0.011^{c}$ & $0.07 \pm 0.003^{d}$ & $0.06 \pm 0.005^{d}$ & $0.06 \pm 0.003^{d}$ & $0.04 \pm 0.008^{\mathrm{a}}$ \\
\hline \multirow[t]{2}{*}{ (mg/tube) } & Low & $0.05 \pm 0.005^{\mathrm{a}}$ & $0.30 \pm 0.010^{\mathrm{b}^{*}}$ & $0.29 \pm 0.015^{c^{*}}$ & $0.10 \pm 0.007^{\mathrm{d}^{*}}$ & $0.07 \pm 0.003^{e}$ & $0.07 \pm 0.004^{e}$ & $0.07 \pm 0.004^{\mathrm{e}^{*}}$ \\
\hline & High & $0.05 \pm 0.026^{a}$ & $0.29 \pm 0.005^{b^{*}}$ & $0.28 \pm 0.005^{b^{*}}$ & $0.19 \pm 0.005^{c^{* *}}$ & $0.11 \pm 0.008^{\mathrm{d}^{*}}$ & $0.13 \pm 0.010^{\mathrm{d}^{*}}$ & $0.10 \pm 0.002^{\mathrm{d}^{* *}}$ \\
\hline $18: 0$ & 0 & $0.50 \pm 0.011^{\mathrm{a}}$ & $0.51 \pm 0.041^{\mathrm{a}}$ & $0.58 \pm 0.014^{b}$ & $0.74 \pm 0.056^{c}$ & $0.73 \pm 0.020^{c}$ & $0.71 \pm 0.016^{c}$ & $0.73 \pm 0.019^{c}$ \\
\hline \multirow[t]{2}{*}{ (mg/tube) } & Low & $0.53 \pm 0.019^{a}$ & $0.53 \pm 0.009^{a}$ & $0.53 \pm 0.022^{\mathrm{a}^{*}}$ & $0.67 \pm 0.019^{b^{*}}$ & $0.69 \pm 0.018^{b c^{*}}$ & $0.72 \pm 0.010^{c}$ & $0.73 \pm 0.010^{c}$ \\
\hline & High & $0.53 \pm 0.006^{\mathrm{a}}$ & $0.53 \pm 0.003^{a}$ & $0.52 \pm 0.017^{\mathrm{a}^{*}}$ & $0.54 \pm 0.015^{5^{* *}}$ & $0.58 \pm 0.015^{b^{* *}}$ & $0.65 \pm 0.017^{c^{*}}$ & $0.68 \pm 0.007^{c^{*}}$ \\
\hline VFA & 0 & $434.1 \pm 4.79^{a}$ & $436.4 \pm 7.77^{a}$ & $469.6 \pm 16.80^{b}$ & $541.7 \pm 12.61^{c}$ & $545.7 \pm 8.57^{c}$ & $585.2 \pm 30.61^{d}$ & $567.6 \pm 15.93^{d}$ \\
\hline \multirow[t]{2}{*}{ ( $\mu \mathrm{mol} /$ tube) } & Low & $434.0 \pm 9.61^{\mathrm{a}}$ & $437.7 \pm 6.01^{\mathrm{a}}$ & $460.6 \pm 3.09^{b}$ & $527.9 \pm 6.54^{\mathrm{cd}}$ & $542.9 \pm 4.34^{\mathrm{de}}$ & $557.0 \pm 7.23^{\mathrm{e}^{*}}$ & $551.4 \pm 5.35^{e}$ \\
\hline & High & $449.1 \pm 16.6^{a}$ & $433.0 \pm 8.91^{\mathrm{a}}$ & $468.5 \pm 21.71^{b}$ & $531.8 \pm 8.25^{c}$ & $549.7 \pm 6.14^{c d}$ & $562.1 \pm 17.97^{\mathrm{d}^{*}}$ & $559.4 \pm 2.82^{d}$ \\
\hline $22: 6 n-3$ & Low & $0.07 \pm 0.005^{a}$ & $0.07 \pm 0.002^{\mathrm{a}}$ & $0.06 \pm 0.002^{b}$ & $0.02 \pm 0.001^{c}$ & $0.02 \pm 0.001^{c}$ & $0.02 \pm 0.003^{c}$ & $0.01 \pm 0.000^{d}$ \\
\hline (mg/tube) & High & $0.31 \pm 0.018^{a}$ & $0.30 \pm 0.012^{a}$ & $0.29 \pm 0.011^{a}$ & $0.17 \pm 0.002^{b}$ & $0.11 \pm 0.004^{c}$ & $0.09 \pm 0.012^{c}$ & $0.06 \pm 0.006^{d}$ \\
\hline
\end{tabular}

CLA conjugated linoleic acid, VA vaccenic acid, VFA volatile fatty acids

For each fatty acids, subscript * represents different $(P<0.05)$ compared to $0 \mathrm{mg} /$ tube $22: 6 n-3$ and ${ }^{*}$ represents different $(P<0.05)$ compared to 0 and $0.1 \mathrm{mg} /$ tube $22: 6 \mathrm{n}-3$ at the respective time point

Within each row means with different superscripts (a-e) are significantly different $(P<0.05)$

stearic acid-producing groups respectively [16]. Butyrivibrio fibrisolvens $\mathrm{D} 1$ and $B$. proteoclasticus $\mathrm{P} 18$ were chosen for this study as a representative from each group. However, the type species $B$. fibrisolvens D1 showed high butyrate kinase activity which is atypical to the majority of $B$. fibrisolvens isolates [17].

Previous studies carried out with $B$. fibrisolvens and $B$. proteoclasticus in M2 medium failed to show hydrogenation of $22: 6 n-3[2,10]$. The reason for this is probably the high concentration of 22:6n-3 used in these studies $(50 \mu \mathrm{g} / \mathrm{mL})$ which may have affected the growth of the bacteria. Wallace et al. [4] showed growth to be a prerequisite for $B$. proteoclasticus $\mathrm{P} 18$ in order to form stearic acid (18:0) from 18:2n-6. If this is also true for 22:6n-3 biohydrogenation, failure to grow when $22: 6 n-3$ is present in previous experiments $[2,10]$ possibly explains the absence of 22:6n-3 biohydrogenation. To reduce the inhibitory effect of $22: 6 n-3$ on growth, the concentration of $22: 6 n-3$ in the medium can be lowered or substances which lower the toxicity of $22: 6 n-3$ should be included in the medium. Harfoot et al. [18] showed that biohydrogenation was stimulated by rumen fluid particles, enabling FA biohydrogenation by ruminal bacteria. Experiments performed in our lab also showed addition of autoclaved-uncentrifuged rumen fluid stimulated the biohydrogenation of 22:6n-3 in mixed cultures of rumen bacteria (Escobar M, Vlaeminck B and Fievez $\mathrm{V}$, unpublished results). Hence, we used autoclaveduncentrifuged rumen fluid to prepare the growth medium. Additionally we used a lower concentration of 22:6n-3 than the concentration reported previously $(50 \mu \mathrm{g} / \mathrm{mL})[2,10]$.

Butyrivibrio fibrisolvens grew at low concentrations of 22:6n-3 without metabolizing it. Maia et al. [2] showed that growth of $B$. fibrisolvens JW11 was not initiated until all 18:2n-6 was metabolized and converted to VA, such phenomenon was not observed with $22: 6 n-3$. The failure of $B$. fibrisolvens D1 to metabolize $22: 6 n-3$ in the current experiment might indicate they do not possess the necessary enzymes for 22:6n-3 biohydrogenation. However, further studies are warranted as B. fibrisolvens D1 is atypical to other B. fibrisolvens in general.

In contrast with previous reports [10], we found $B$. proteoclasticus $\mathrm{P} 18$ is able to hydrogenate $22: 6 n-3$. To our knowledge, this is the first report demonstrating 22:6n-3 biohydrogenation by a pure bacterial species. 
Temporal changes in 22:6n-3, VFA and $\mathrm{OD}_{600}$ during the course of the incubation might indicate $B$. proteoclasticus must be growing to biohydrogenate 22:6n-3, with little transformation occurring during the stationary phase. Such observations were also made when demonstrating the capability of $B$. proteoclasticus $\mathrm{P} 18$ to form 18:0 from 18:2n-6 [4]. Stationary-phase bacteria were reported to be much less active in hydrogenation of $18: 2 n-6$ than growing cells $[4,19]$. This was explained by a limited supply of reducing equivalents once the energy sources in the medium had been depleted [4] as the conversion of CLA to VA is NADH-dependent [20]. It seems probable that a similar mechanism explains the variation in rate of disappearance of $22: 6 n-3$ during the course of the incubation period. It is however not clear whether growth or activity per se is needed for biohydrogenation, or that the association of disappearance of 22:6n-3, VFA and $\mathrm{OD}_{600}$ is merely a reflection of changes in the culture closely associated with growth and activity (e.g. biomass production, redox potential).

The metabolism of 22:6n-3 resulted in the appearance of numerous compounds eluting during GC analysis between 22:0 and 22:6n-3. It has been speculated before that ruminal hydrogenation of 22:6n-3 yields intermediates with 5 or 6 double bonds, containing at least one trans double bond [1]. The position of the double bonds in the most abundant $22: 5$ isomer $(\Delta 5, \Delta 10, \Delta 13, \Delta 16$, $\Delta 19-22: 5)$ suggest the formation of this intermediate involves izomerisation of the cis- 4 double bond and reduction of the cis-7 double bond [21]. Initial izomerisation of the cis- 4 double bond of 22:6n-3 would result in the formation of a conjugated product $(\Delta 5, \Delta 7, \Delta 10, \Delta 13$, $\Delta 16, \Delta 19-22: 6)$. However, in the present series of experiments, no accumulation of products eluting in the GC chromatogram with a retention time greater than 22:6n3 was observed, a region where conjugated isomers of 22:6 would be expected to elute with the polar column used in the present study. The lack of accumulation of a conjugated FA might indicate they are transient products which did not accumulate at the time of sampling. Alternatively, this might also indicate the initial product of 22:6n-3 metabolism is not a conjugated FA. The accumulation of 22:5 isomers produced during the initial stages of 22:6n-3 biohydrogenation was transient, when the initial 22:6n-3 concentration was low, and these isomers were subsequently hydrogenated to more saturated 22:4, 22:3 and 22:2 isomers. The existence of two isomers with identical double bond position (peak 5 and 7 as $\Delta 13, \Delta 16, \Delta 20-22: 3$ and peak 9 and 11 as $\Delta 16, \Delta 20$ 22:2) indicates double bonds in the trans configuration must be present. It is unclear to what extent the increases in polyenoic trans fatty acids may offset some of the expected benefits from the enrichment of 22:6n-3 in ruminant derived foods [21].
Butyrivibrio proteoclasticus is the only known ruminal bacterium with the capacity to biohydrogenate 18carbon FA to 18:0. Previous incubations with rumen fluid have established that 22:6n-3 inhibits the complete hydrogenation of 18-carbon unsaturated FA causing trans 18:1 isomers to accumulate [8]. This is thought to be related to the toxic effects of $22: 6 n-3$ on the growth and metabolic activity of $B$. proteoclasticus [22]. However, in vivo studies have failed to show the relationship between 18:0 flow to the duodenum and B. proteoclasticus DNA [7, 23]. Based on the findings of present study we suggest that $B$. proteoclasticus probably starts to hydrogenate 22:6n-3 before converting 18:1 isomers to 18:0. Biohydrogenation is required to lower toxicity and therefore the reduction of products containing more double bonds are a greater priority which explains the lack of 18:1 reduction at time points where biohydrogenation of 22:6n-3 did occur. These findings possibly explain the lack of relationship of duodenal 18:0 to the duodenum and B. proteoclasticus DNA [7, 23].

\section{Conclusions}

Butyrivibrio proteoclasticus P18 is able to hydrogenate 22:6n-3 in vitro. The rate and extent of biohydrogenation depended on the initial concentration of 22:6n-3 and the duration of incubation. Several 22:5, 22:4, 22:3 and 22:2 isomers were identified. The products formed irrespective of the initial concentrations of $22: 6 n-3$ and type of growth media suggests $B$. proteoclasticus $\mathrm{P} 18$ had a consistent pathway of 22:6n-3 hydrogenation. During the simultaneous presence of both $18: 2 n-6$ and 22:6n-3, B. proteoclasticus P18 initiated 22:6n-3 metabolism before converting 18:1 isomers into 18:0. Under the current culture conditions, $B$. fibrisolvens D1 failed to hydrogenate 22:6n-3.

\section{Methods}

Microorganisms and cultivation

Butyrivibrio fibrisolvens D1 (DSM 3071) and B. proteoclasticus P18 were selected for this study. Butyrivibrio fibrisolvens D1 was purchased from DSMZ (Deutsche Sammlung von Mikroorganismen und Zellkulturen $\mathrm{GmbH}$, Braunschweig, Germany) and B. proteoclasticus P18 was obtained from the culture collection of the Rowett Institute of Nutrition and Health (University of Aberdeen, Bucksburn, Aberdeen AB21 9SB, UK). Butyrivibrio medium (DSMZ: medium 704) was slightly modified: VFA mixture, haemin and glycerol were omitted from the basic medium and $\mathrm{L}$-cysteine- $\mathrm{HCl}$ was used as the only reducing agent $(0.5 \mathrm{~g} / \mathrm{l})$. The preparation method of rumen fluid and the rumen fluid/buffer ratio were also modified (Table 1).

Autoclaved-uncentrifuged or -centrifuged rumen fluids were used for the growth media preparation. Rumen 
fluid was collected from 3 mature wethers, fitted with a ruminal cannula, fed grass hay and a commercial grain concentrate twice a day according to their maintenance requirements. To obtain the centrifuged rumen fluid, rumen fluid collected from cannulated wethers, was filtered through a sieve with a pore size of $1 \mathrm{~mm}$ and then fine particles were removed from the filtrate by centrifugation at $10,000 \mathrm{~g}$ for $20 \mathrm{~min}$ at $4{ }^{\circ} \mathrm{C}$. The supernatant was sterilized by autoclaving for $20 \mathrm{~min}$ at $121{ }^{\circ} \mathrm{C}$ and stored frozen at $-20{ }^{\circ} \mathrm{C}$. The stored rumen fluid was thawed before use and any new precipitates formed were removed by centrifugation at $12,000 \mathrm{~g}$ for $15 \mathrm{~min}$ at $4{ }^{\circ} \mathrm{C}$. For autoclaved-uncentrifuged rumen fluid, rumen fluid collected from cannulated wethers was filtered through a sieve with a pore size of $1 \mathrm{~mm}$ and autoclaved $(20 \mathrm{~min}$ at $121{ }^{\circ} \mathrm{C}$ ), and used without further processing.

In vitro incubations were carried out anaerobically at $39{ }^{\circ} \mathrm{C}$ under continuous shaking in Hungate-type tubes (16 mm dia., $125 \mathrm{~mm}$ long; Bellco Glass, Vineland, NJ, USA) containing $9.5 \mathrm{ml}$ of medium and closed with screw caps fitted with butyl rubber septa (Chemglass Life Sciences, Vineland, NJ, USA), and autoclaved for $20 \mathrm{~min}$ at $121{ }^{\circ} \mathrm{C}$. Inoculum volumes were $5 \%(\mathrm{v} / \mathrm{v})$ of a fresh culture that was grown in medium 704 for $12 \mathrm{~h}$ $\left(\mathrm{OD}_{600} \approx 1.7\right)$. Growth was determined by measuring the culture density at $600 \mathrm{~nm}$ (Ultraspec10, Amersham Biosciences corp., Piscataway, NJ, USA). At the end of the experiment the incubations were stopped by placing the tubes in ice water. $\mathrm{pH}$ was measured (Hanna instruments, Temse, Belgium) and culture contents were sampled for VFA and long chain FA (LCFA) analysis.

\section{Fatty acid solution}

Fatty acid solutions were prepared by dispersing $200 \mathrm{mg}$ of 22:6n-3 (Nu-check-Prep., Elysian, MN, USA) in $3.33 \mathrm{~mL}$ of a $0.06 \mathrm{M}$ Tween-80 (Sigma Aldrich, St Louis, MO) solution. Then $0.25 \mathrm{~mL}$ of $3 \mathrm{M} \mathrm{NaOH}$ was added to obtain a clear solution. This solution was diluted with distilled water to achieve a final 22:6n-3 concentration of $10 \mathrm{mg} / \mathrm{mL}$. The amount of Tween-80 and $\mathrm{NaOH}$ in all the tubes was kept the same by using a blank solution (prepared with Tween-80 and $\mathrm{NaOH}$ only). The required amount of the FA solution was added before autoclaving individually to each Hungate tube.

\section{In vitro experiments}

Previous experiments performed with Butyrivibrio species in the medium containing centrifuged rumen fluid failed to hydrogenate $22: 6 n-3[2,10]$. As such, experiments 1-5 (Table 1) were conducted using the growth medium containing autoclaved-uncentrifuged rumen fluid. In experiment $1, B$. fibrisolvens was grown in the medium containing either 20 or $50 \%(\mathrm{v} / \mathrm{v})$ autoclaveduncentrifuged rumen fluid. The concentration of $22: 6 n-3$ used $(20 \mu \mathrm{g} / \mathrm{mL})$ was lower than the previously reported value $(50 \mu \mathrm{g} / \mathrm{mL})[2,10]$. All treatments were conducted with 3 replicates.

Since we saw the 22:6n-3 disappearance by $B$. proteoclasticus in the medium containing $50 \% \quad(\mathrm{v} / \mathrm{v})$ autoclaved-uncentrifuged rumen fluid, additional experiments were conducted in this medium (Table 1). Influence of headspace gas (Exp. 2), incubation period (Exp. 3 ) and initial concentration of 22:6n-3 (Exp. 4) were studied in these experiments. Butyrivibrio proteoclasticus is the only stearic acid forming rumen bacteria so far identified. Formation of stearic acid (18:0) may be affected in the presence of $22: 6 n-3$ as $22-\mathrm{C}$ FA are more toxic than the 18-C FA. As such influence of 18:2n-6 $(40 \mu \mathrm{g} / \mathrm{mL})$ on biohydrogenation of $22: 6 n-3(0,10$ and $40 \mu \mathrm{g} / \mathrm{mL}$ ) was studied in experiment 5 . All treatments were performed in duplicate (analytical replicates) with inoculum from two different culture tubes (biological replicates).

Experiments 6-8 were conducted using autoclavedcentrifuged rumen fluid (Table 1). In experiment 6, $B$. fibrisolvens was grown with different concentrations of 22:6n-3 and growth (culture density) was monitored during the experiment. Lag time for the growth was determined based on the time point at which the increase in $\mathrm{OD}_{600}$ initiated. Linoleic acid $(18: 2 n-6)$ was used as the positive control. Treatments were performed in duplicate (analytical replicates) with inoculum from three different culture tubes (biological replicates).

In experiment 7 , we saw the disappearance of $22: 6 n-3$ $(20 \mu \mathrm{g} / \mathrm{mL})$ by $B$. proteoclasticus in the medium containing $20 \%(\mathrm{v} / \mathrm{v})$ autoclaved-centrifuged rumen fluid after $24 \mathrm{~h}$ incubation. Kinetics of this disappearance was studied in experiment 8 along with the growth of the bacteria by measuring increase in culture density $\left(\mathrm{OD}_{600}\right)$ at the time of tube withdrawal. Three analytical replicates were used for each treatment.

\section{Analysis and calculation}

For VFA analysis, $2 \mathrm{~mL}$ of incubation medium were collected and acidified with $200 \mu \mathrm{L}$ of formic acid which contained the internal standard (10 mg of 2-ethyl butyric acid $/ \mathrm{mL}$ formic acid). After $15 \mathrm{~min}$ centrifugation at $4^{\circ}$ $\mathrm{C}$ and $22,000 \mathrm{~g}$, supernatant was filtered and an aliquot was transferred into a $1.5 \mathrm{~mL}$ glass vial. Samples were stored at $4{ }^{\circ} \mathrm{C}$ until VFA analysis using gas chromatography (HP 7890A, Agilent Technologies, Diegem, Belgium) equipped with a FID detector and a Supelco Nukol capillary column $(30 \mathrm{~m} \times 0.25 \mathrm{~mm} \times 0.25 \mu \mathrm{m}$, Sigma-Aldrich, Diegem, Belgium). The temperature program was as follows: $120{ }^{\circ} \mathrm{C}$ at injection for $0.2 \mathrm{~min}$; increased at $10{ }^{\circ} \mathrm{C} / \mathrm{min}$ until $180{ }^{\circ} \mathrm{C}$ and remained at this temperature for $3 \mathrm{~min}$; injector temperature: $250{ }^{\circ} \mathrm{C}$; detector temperature $255{ }^{\circ} \mathrm{C}$. For this temperature 
program, $0.3 \mu \mathrm{L}$ was injected with a split/splitless ratio of $25: 1$ using $\mathrm{H}_{2}$ as carrier gas at $0.8 \mathrm{~mL} / \mathrm{min}$. VFA peaks were identified based on their retention times, compared to external standards (Sigma Aldrich, St Louis, MO).

The remainder of the content in the Hungate tubes after removal of $2 \mathrm{~mL}$ for VFA analysis $(8 \mathrm{~mL} /$ tube) was freeze-dried for LCFA analysis and FA were methylated as described by Vlaeminck et al. [9]. Analysis of the FA methyl esters (FAME) was carried out using a gas chromatograph (HP7890A, Agilent Technologies, Diegem, Belgium) using a SP-2560 column (75 m x $0.18 \mathrm{~mm}$, i.d. $\mathrm{x}$ $0.14 \mu \mathrm{m}$ thickness, Supelco Analytical, Bellefonte, USA) and a flame ionization detector. The temperature program was initially $70{ }^{\circ} \mathrm{C}$ for $2 \mathrm{~min}$, increasing at $15{ }^{\circ} \mathrm{C} / \mathrm{min}$ to $150{ }^{\circ} \mathrm{C}$, followed by a second increase at $1{ }^{\circ} \mathrm{C} / \mathrm{min}$ up to $165{ }^{\circ} \mathrm{C}$ and holding for $12 \mathrm{~min}$, followed by a third increase at $5{ }^{\circ} \mathrm{C} / \mathrm{min}$ to $210{ }^{\circ} \mathrm{C}$, held at $210{ }^{\circ} \mathrm{C}$ for $20 \mathrm{~min}$, increased at $5{ }^{\circ} \mathrm{C} / \mathrm{min}$ to $220{ }^{\circ} \mathrm{C}$ and held at $220{ }^{\circ} \mathrm{C}$ for $15 \mathrm{~min}$. Inlet and detector temperatures were 250 and $255{ }^{\circ} \mathrm{C}$, respectively. The split ratio was 50:1. Hydrogen was used as the carrier gas at a flow rate of $1 \mathrm{~mL} / \mathrm{min}$. Identities of peaks were determined using mixtures of methyl ester standards (GLC463, Nu-Check-Prep., Inc., Elysian, MN, USA).

Quantification of FA was based on the area of the internal standard and on the conversion of peak areas to the weight of FA by a theoretical response factor for each FA [24, 25].

\section{Structural analysis of fatty acid intermediates}

Methyl esters not contained in commercially available standards were identified based on GC-MS analysis of DMOX derivatives prepared from FAME. Prior to preparation of DMOX derivatives, FAME were fractionated using $\mathrm{Ag}^{+}$-SPE columns $(750 \mathrm{mg} / 6 \mathrm{~mL}$, Supelco, Bellefonte, PA, USA). Columns were activated with $4 \mathrm{~mL}$ acetone, followed by $4 \mathrm{~mL}$ hexane. The FAME of selected samples, dissolved in $1 \mathrm{~mL}$ hexane, were loaded on the column and eluted with hexane containing increasing amounts of acetone (v/v): $6 \mathrm{~mL}(99 / 1), 2 \times$ $3 \mathrm{~mL}(96 / 4), 2 \times 3 \mathrm{~mL}$ (90/10), $2 \times 3 \mathrm{~mL}(0 / 100)$. This was followed by elution with acetone containing increasing amounts of acetonitrile (v/v): $2 \times 3 \mathrm{~mL}(98 / 2), 2 \times$ $3 \mathrm{~mL}(96 / 4), 2 \times 3 \mathrm{~mL}(94 / 6), 2 \times 3 \mathrm{~mL}(90 / 10)$ and $2 \times$ $3 \mathrm{~mL}(80 / 20)$. All fractions were taken to dryness in a stream of $\mathrm{N}_{2}$, dissolved in hexane and used for analysis of FAME by GC, as described above, and preparation of 4, 4-dimethyloxazoline (DMOX) derivatives.

DMOX derivatives of FA were prepared by using a modified procedure [26]. Briefly, FAMEs were converted into DMOX derivatives with $500 \mu \mathrm{L}$ 2-amino-2-methyl-1-propanol under a nitrogen atmosphere at $170{ }^{\circ} \mathrm{C}$ overnight. DMOX derivatives were extracted twice with diethyl ether/ $\mathrm{n}$-hexane $(1: 1, \mathrm{v} / \mathrm{v})$ and sodium chloride-saturated water.
The organic layer was dried with anhydrous sodium sulphate for $1 \mathrm{~h}$, followed by evaporation until dry under nitrogen. The DMOX derivatives were dissolved in hexane.

Identification of the DMOX derivatives of the biohydrogenation intermediates was based on electron impact ionisation spectra obtained by gas chromatography-mass spectrometry (GC-MS), using a gas chromatograph (Trace2D-GC, Thermo Electron Corporation, Waltham, MA, USA) coupled to a quadrupole mass detector (DSQII, Thermo Electron Corporation) under an ionisation voltage of $70 \mathrm{eV}$, using helium as carrier gas. The ion source and interface temperatures were maintained at $200{ }^{\circ} \mathrm{C}$ and $250{ }^{\circ} \mathrm{C}$, respectively. The column was a SLB $5 \mathrm{~ms}$ capillary column $(60 \mathrm{~m} \times 0.25 \mathrm{~mm}$, i.d. $\mathrm{x}$ $0.25 \mu \mathrm{m}$ thickness, Supelco Analytical, Bellefonte, USA). The electron impact ionization spectra obtained were used to locate double bonds based on atomic mass unit (amu) distances with an interval of $12 \mathrm{amu}$ between the most intense peaks of clusters of ions containing $n$ and $\mathrm{n}-1$ carbon atoms, being interpreted as cleavage of the double bond between carbon $n$ and $n+1$ in the fatty acid moiety.

\section{Statistical analysis}

All statistical analysis was performed using SAS version 9.4 (SAS Institute Inc., Cary, NC). A least squares mean ANOVA in the GLM procedure using 22:6n-3 level (Exp. 1, 4, 5 and 6) or incubation time (Exp. 3 and 8) or headspace gas (Exp. 2) as factors was used to test time and treatment effects. The Tukey-Kramer test was performed to assess which treatments differed in case of multiple $(>2)$ treatments. The differences among means with $P<0.05$ were considered to be statistically significant.

\section{Abbreviations \\ CLA, conjugated linoleic acid; FA, Fatty acid; FAME, Fatty acid methyl esters; OD, optical density; PUFA, polyunsaturated fatty acids; VA, vaccenic acid; VFA: volatile fatty acids.}

\section{Acknowledgements}

The authors thank Charlotte Melis for performing FA extraction.

\section{Funding}

The study was funded by the Fund for Scientific Research-Flanders (Belgium) and the Special Research Fund of the Ghent University. Post-doctoral fellowship of J and BV, and doctoral fellowship of ME are financed by the Fund for Scientific Research-Flanders (Belgium) and the Special Research Fund of the Ghent University.

\section{Availability of data and materials}

The data supporting the conclusion of this article are included within the article.

\section{Authors' contribution}

$J J, B V$ and VF conceived and designed the experiments. JJ and ME carried out the experiments. JJ performed statistical analysis and wrote the manuscript. BV, RJW and VF provided critical discussions during revision. All authors read and approved the final manuscripts. 


\section{Competing interests}

The authors declare that they have no competing interests.

\section{Consent to publish}

Not applicable.

\section{Ethics and consent to participate}

Rumen fluid for the media preparation was collected from 3 fistulated sheep maintained by the Institute for Agricultural and Fisheries Research (ILVO, Belgium). Fistulation was approved by the ethical commission (file number $114,2009)$ of the ILVO.

\section{Author details}

'Laboratory for Animal Nutrition and Animal Product Quality, Ghent University, Proefhoevestraat 10, 9090 Melle, Belgium. ${ }^{2}$ Rowett Institute of Nutrition and Health, University of Aberdeen, Bucksburn, Aberdeen AB21 9SB, UK.

Received: 17 September 2015 Accepted: 30 May 2016

Published online: 10 June 2016

\section{References}

1. Jenkins TC, Wallace RJ, Moate PJ, Mosley EE. BOARD-INVITED REVIEW: Recent advances in biohydrogenation of unsaturated fatty acids within the rumen microbial ecosystem. J Anim Sci. 2008:86:397-412.

2. Maia MRG, Chaudhary LC, Bestwick CS, Richardson AJ, McKain N, Larson TR, Graham IA, Wallace RJ. Toxicity of unsaturated fatty acids to the biohydrogenating ruminal bacterium, Butyrivibrio fibrisolvens. BMC Microbiol. 2010;10:52.

3. Harfoot CG, Hazlewood GP. Lipid metabolism in the rumen. In: Hobson PN, editor. The Rumen Microbial Ecosystem. New york: Elsvier Science publishing; 1988. p. 285-322.

4. Wallace RJ, Chaudhary LC, McKain N, McEwan NR, Richardson AJ, Vercoe PE, Walker ND, Paillard D. Clostridium proteoclasticum: A ruminal bacterium that forms stearic acid from linoleic acid. FEMS Microbiol Lett. 2006;265:195-201.

5. Shingfield KJ, Bernard L, Leroux C, Chilliard Y. Role of trans fatty acids in the nutritional regulation of mammary lipogenesis in ruminants. Animal. 2010;4: 1140-66.

6. Shingfield KJ, Lee MR, Humphries DJ, Scollan ND, Toivonen V, Reynolds CK Beever DE. Effect of incremental amounts of fish oil in the diet on ruminal lipid metabolism in growing steers. Br J Nutr. 2010;104:56-66.

7. Shingfield KJ, Kairenius P, Arola A, Paillard D, Muetzel S, Ahvenjarvi S, Vanhatalo A, Huhtanen P, Toivonen V, Griinari JM, Wallace RJ. Dietary fish oil supplements modify ruminal biohydrogenation, alter the flow of fatty acids at the omasum, and induce changes in the ruminal Butyrivibrio population in lactating cows. J Nutr. 2012;142:1437-48.

8. AbuGhazaleh AA, Jenkins TC. Short communication: docosahexaenoic acid promotes vaccenic acid accumulation in mixed ruminal cultures when incubated with linoleic acid. J Dairy Sci. 2004:87:1047-50.

9. Vlaeminck B, Braeckman T, Fievez V. Rumen metabolism of 22:6n-3 in vitro is dependent on its concentration and inoculum size, but less dependent on substrate carbohydrate composition. Lipids. 2014;49:517-25.

10. Maia MR, Chaudhary LC, Figueres L, Wallace RJ. Metabolism of polyunsaturated fatty acids and their toxicity to the microflora of the rumen. Ant van Leeuw. 2007:91:303-14.

11. Sakurama H, Kishino S, Mihara K, Ando A, Kita K, Takahashi S, Shimizu S, Ogawa J. Biohydrogenation of C20 polyunsaturated fatty acids by anaerobic bacteria. J Lipid Res. 2014:55:1855-63.

12. Christie WW. Some recent advances in the chromatographic analysis of lipids. Analusis. 1998;26:34-9.

13. Yu QT, Liu BN, Zhang JY, Huang ZH. Location of double bonds in fatty acids of fish oil and rat testis lipids. Gas chromatography-mass spectrometry of the oxazoline derivatives. Lipids. 1989:24:79-83.

14. Dobson G, Christie WW. Structural analysis of fatty acids by mass spectrometry of picolinyl esters and dimethyloxazoline derivatives. TrAC Trends Analyt Chem. 1996;15:130-7.

15. Polan CE, McNeill JJ, Tove SB. Biohydrogenation of Unsaturated Fatty Acids by Rumen Bacteria. J Bacteriol. 1964;88:1056-64.

16. Paillard D, McKain N, Chaudhary LC, Walker DW, Pizette F, Koppova I, McEwan NR, Kopecny J, Vercoe PE, Louis P, Wallace RJ. Relation between phylogenetic position, lipid metabolism and butyrate production by different Butyrivibrio-like bacteria from the rumen. Ant van Leeuw. 2007:91:417-22.

17. Forster RJ, Teather RM, Gong J, Deng SJ. $16 \mathrm{~S}$ rDNA analysis of Butyrivibrio fibrisolvens: phylogenetic position and relation to butyrate-producing anaerobic bacteria from the rumen of white-tailed deer. Lett Appl Microbiol. 1996;23:218-22

18. Harfoot CG, Noble RC, Moore JH. Food particles as a site for biohydrogenation of unsaturated fatty acids in the rumen. Biochem J. 1973;132:829-32.

19. Kim YJ, Liu RH, Bond DR, Russell JB. Effect of linoleic acid concentration on conjugated linoleic acid production by Butyrivibrio fibrisolvens A38. Appl Environ Microbiol. 2000:66:5226-30.

20. Hunter WJ, Baker FC, Rosenfeld IS, Keyser JB, Tove SB. Biohydrogenation of unsaturated fatty acids. Hydrogenation by cell-free preparations of Butyrivibrio fibrisolvens. J Biol Chem. 1976;251:2241-7.

21. Kairenius $P$, Toivonen $V$, Shingfield KJ. Identification and ruminal outflow of long-chain fatty acid biohydrogenation intermediates in cows fed diets containing fish oil. Lipids. 2011:46:587-606.

22. Wasowska I, Maia MR, Niedzwiedzka KM, Czauderna M, Ribeiro JM, Devillard E, Shingfield KJ, Wallace RJ. Influence of fish oil on ruminal biohydrogenation of C18 unsaturated fatty acids. Br J Nutr. 2006:95:1199-211.

23. Huws SA, Lee MR, Muetzel SM, Scott MB, Wallace RJ, Scollan ND. Forage type and fish oil cause shifts in rumen bacterial diversity. FEMS Microbiol Ecol. 2010;73:396-407.

24. Ackman RG, Sipos JC. Application of specific response factors in the gas chromatographic analysis of methyl esters of fatty acids with flame ionization detectors. J Am Oil Chem Soc. 1964:41:377-8.

25. Wolff RL, Bayard CC, Fabien RJ. Evaluation of sequential methods for the determination of butterfat fatty acid composition with emphasis on tran-18: 1 acids. Application to the study of seasonal variations in French butters. $J$ Am Oil Chem Soc. 1995;72:1471-83.

26. Destaillats F, Trottier JP, Galvez JG, Angers P. Analysis of a-linolenic acid biohydrogenation intermediates in milk fat with emphasis on conjugated linolenic acids. J Dairy Sci. 2005:88:3231-9.

\section{Submit your next manuscript to BioMed Central and we will help you at every step:}

- We accept pre-submission inquiries

- Our selector tool helps you to find the most relevant journal

- We provide round the clock customer support

- Convenient online submission

- Thorough peer review

- Inclusion in PubMed and all major indexing services

- Maximum visibility for your research

Submit your manuscript at www.biomedcentral.com/submit
Biomed Central 